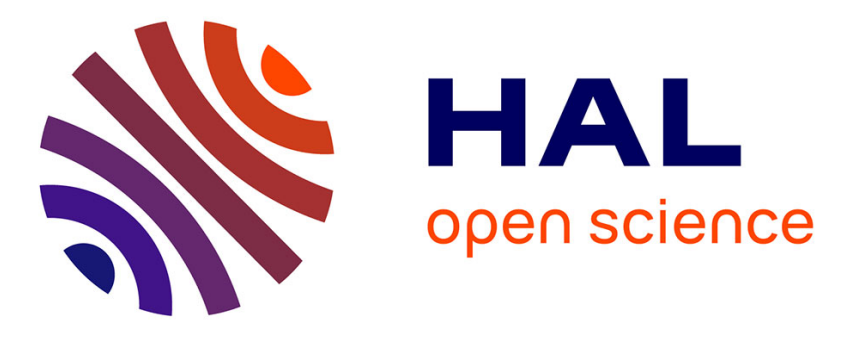

\title{
Supporting every school to become a foundation for healthy lives
}

Didier Jourdan, Nicola J Gray, Margaret M Barry, Sonja Caffe, Christophe Cornu, Fatou Diagne, Fadi El Hage, Mychelle Farmer, Sean Slade, Michael Marmot, et al.

\section{To cite this version:}

Didier Jourdan, Nicola J Gray, Margaret M Barry, Sonja Caffe, Christophe Cornu, et al.. Supporting every school to become a foundation for healthy lives. The Lancet Child \& Adolescent Health, 2021, 5 (4), pp.295-303. 10.1016/S2352-4642(20)30316-3 . hal-03367605

\section{HAL Id: hal-03367605 https://hal.science/hal-03367605}

Submitted on 18 Nov 2021

HAL is a multi-disciplinary open access archive for the deposit and dissemination of scientific research documents, whether they are published or not. The documents may come from teaching and research institutions in France or abroad, or from public or private research centers.
L'archive ouverte pluridisciplinaire HAL, est destinée au dépôt et à la diffusion de documents scientifiques de niveau recherche, publiés ou non, émanant des établissements d'enseignement et de recherche français ou étrangers, des laboratoires publics ou privés.

\section{(ㅇ)(1) $\$$}

Distributed under a Creative Commons Attribution - NonCommercial - NoDerivatives| 4.0 


\section{Supporting every school to become a foundation for healthy lives}

Didier Jourdan, Nicola J Gray, Margaret M Barry, Sonja Caffe, Christophe Cornu, Fatou Diagne, Fadi El Hage, Mychelle Y Farmer, Sean Slade, Michael Marmot, Susan M Sawyer (affiliations removed, but will be in final print version)

As a setting where children and adolescents live and learn, linked to the family and embedded within the wider community, schools have an important influence on every student's health. Many health interventions have used schools as a platform, often for standalone programmatic initiatives to reduce health risks, and sometimes for more comprehensive approaches, but the interventions, uptake, and sustainability are generally disappointing. Evidence shows that, to improve health and to reduce inequality, all students must attend school from a young age and for as long as possible, and their educational success therein must be maximised. Thus, beyond educational benefits, schools are also important for health. Coherence between each school's policies, structures and systems, human resources, and practices is required to advance both academic and health outcomes. Beyond simply implementing ready-made programmes into schools, health professionals can position themselves as catalysts for structural change as they have many opportunities to advocate for, and participate in, the intersectoral implementation of reforms and innovations in school systems to promote the health of all students.

Introduction The health of children and adolescents is influenced by a complex interplay of biopsychosocial, cultural, environmental, and economic factors.1 As an educational setting where children and adolescents spend a large proportion of their daily lives, school has an important influence on every student's health and wellbeing.2 Simply attending school for longer is associated with better health outcomes, including intergenerational benefits-eg, mothers who are better educated typically have healthier children than mothers who have received less education.3 We have known for more than a century that the provision of healthy food and social support at school improves attendance and increases participation in children and adolescents from disadvantaged communities.4 Globally, growing rates of school participation mean that schools are increasingly recognised as an important platform for enhancing student health, with different formal and informal mechanisms by which these health benefits can occur.s However, there is substantial tension between the aspiration of the health sector to deliver discrete, programmatically based interventions on a range of health topics (such as nutrition, sexuality, parasite eradication, or vaccinations) with more systemic approaches that are required to influence school policies and practices, reshape environments, and build wider community partnerships that underpin sustainable health-promoting practices.6, If positive changes are made, schools have the potential to greatly improve the life chances of children and adolescents. Beyond academic results that influence employment and income prospects, which are themselves strong determinants of future health, schools can equip students to develop general life skills and knowledge that will benefit their health in later life. However, if positive change is not achieved then not only will students miss out on health-maximising skills and knowledge, but also their physical and mental health can be damaged by experiences at school, which can be a powerful amplifier of inequalities. Examples of institutional failings include: bullying; lack of physical activity; and poor nutrition and poor support for students with long-term health conditions (including disabilities), those from refugee backgrounds, and those who identify as LGBTI. The intense national debates about the reopening of schools during the COVID19 pandemic have laid bare the interconnectedness of health and education inequalities, which can worsen when schools close.s,9 The COVID-19 pandemic is unlikely to be an isolated global health emergency; therefore, our societies and school systems must become more resilient for the future. In this Viewpoint, we will highlight the value of health professionals thinking more strategically about their roles in school health, beyond their traditional roles of providing health services and delivering curriculum material about health-based subjects. Improving the health of all students requires a focus on reducing health inequalities, which requires structural changes that health professionals can help to bring about. We will also challenge health-services researchers to consider the clash of evidence-based practice and practice-based evidence that might occur when designing and evaluating school-based studies.

Schools and health: new challenges for an old relationship All civilisations pass down prescriptive advice about health as part of collective wisdom, and since their foundation in the 19th century, contemporary school systems have been mandated to contribute to the improvement of population health. The knowledge that positive health behaviours can be acquired in childhood and adolescence has led political authorities to assign schools the task of improving health. From lessons about hygiene, tuberculosis, and alcoholism at the end of the 19th century, ${ }_{10}$ to whole school approaches ${ }_{11-17}$ that recognise that the ethos of individual schools affects the health of its students and staff, schools have long been targets for efforts to improve health. These efforts have taken different forms at different times and must be regularly reviewed, in the context of evolving social expectations and new knowledge, to ensure that health promoting actions match the changing health needs of students. There is an emerging evidence base that shows that learning outcomes are improved, social and emotional wellbeing are increased, and health risk behaviours are reduced in response to more holistic or whole school approaches.18-20 Such approaches are typically based on coherence between the school's policies and practices that promote social inclusion and a wider commitment to education and health. The World Bank Human Capital Project recognises that the intersection of good health, nutrition, and education can drive economic growth, and that investment in children and adolescents brings substantial effects and high economic returns.21 Schools are not the only options for investment-we do not want to exclude others, including peer-led community interventions-but schools offer a basic and globally consistent setting for promoting health and wellbeing. Beyond the curriculum, providing safe spaces for girls in low-income and middle-income countries and increasing the availability of clean toilets are good examples of the type of non-programmatic responses from schools that are likely to have positive effects on student

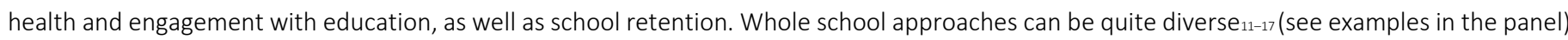
but share two objectives: to improve educational success, and to improve the health and wellbeing of all students and staff. The UN Sustainable Development Goals (SDGs) now form the backdrop to these initiatives.22 Among the 17 SDGs for 2030, the objectives that are most closely related to schools and health are those that link Good Health and Wellbeing (SDG3) with Quality Education (SDG4). Within the SDG agenda, explicit appreciation of the interconnected aspects of these goals also aligns with holistic approaches to student health and wellbeing. Although there is considerable evidence about the relevance of such holistic approaches (eg, WHO's Health Promoting Schools), 11,19,23-25 few countries have successfully implemented them to scale.26-28 A crucial question is how to create the conditions for every school, in the various global educational contexts, to enact practices that positively influence health as part of the everyday life of its students and staff.29 


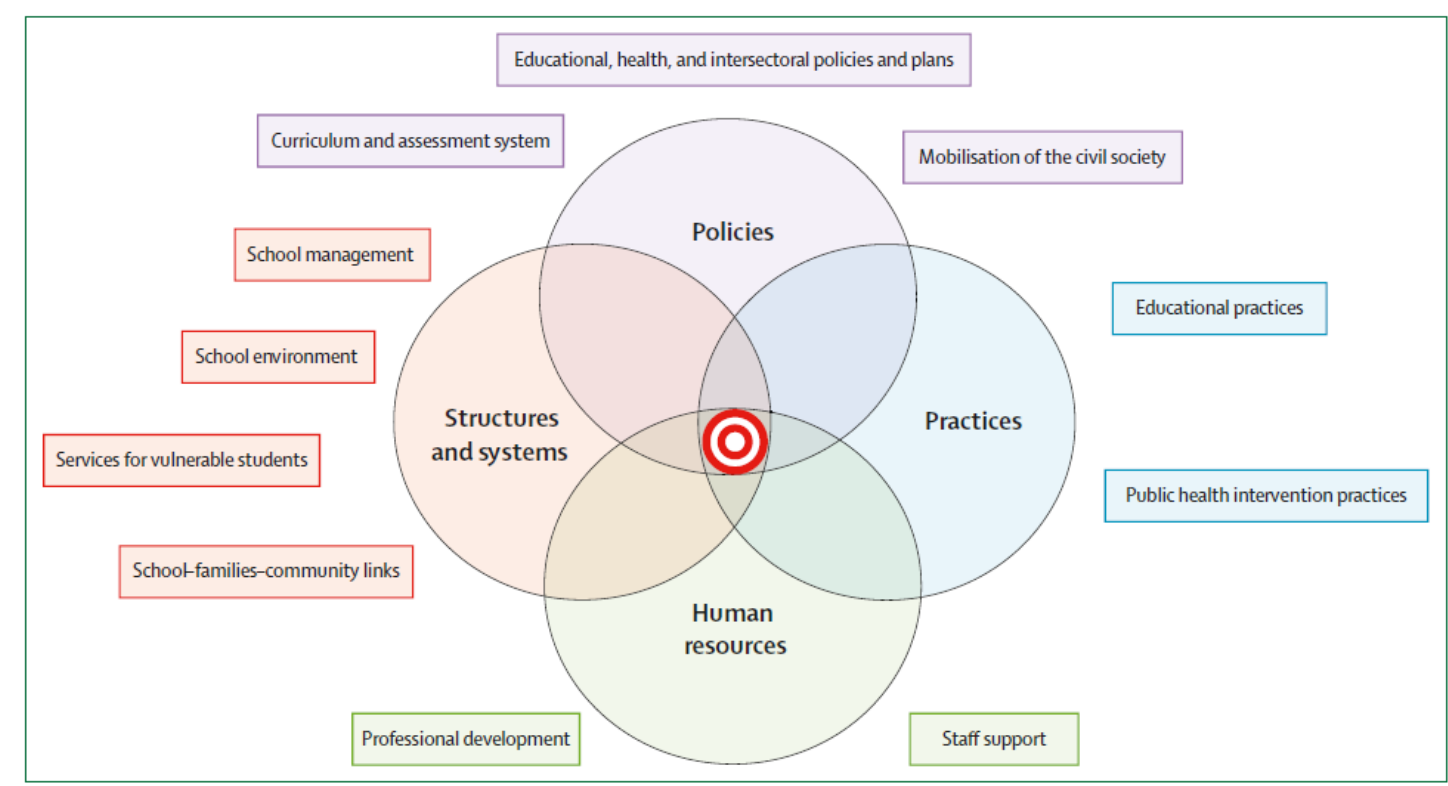

Figure: Factors that affect the implementation of educational reforms for health

The target in the centre of the figure represents the synergy of the four factors.

Health sector support for sustainable change in schools Understanding the so-called modus operandi of school systems is useful background information that should help define the roles of health professionals and health services researchers as future partners and agents of change within schools.30 There is a large evidence base regarding the implementation of education policies and the determinants that hinder or facilitate these processes.31-33 New approaches in complex education systems need to take into account the school culture, the overall coherence of the pedagogy, the constraints that affect the activity (such as the heterogeneity of students, curriculum constraints, and available resources), and the vision and usual practices of staff. ${ }_{34}$ Arguably, four interconnecting levers have to be activated to achieve educational reform: practices; structures and systems; human resources; and policies as shown in the figure.35,36 Table 1 shows how these levers might be focused for two healthrelated issues in school-namely, bullying (with its links to mental health issues) and living with diabetes. These health-related issues are globally relevant, and although there might be substantial resource differences between schools in high-income and low-income countries, they illustrate universal health and wellbeing needs of children and adolescents.

\begin{tabular}{|c|c|c|}
\hline & Bullying & Diabetes \\
\hline Policies & $\begin{array}{l}\text { Anti-bullying policy incorporates consequences for bullying, engagement of } \\
\text { parents, links to responsible social media use, and recognises bullying as a } \\
\text { potential cause of school absenteeism }\end{array}$ & $\begin{array}{l}\text { Long-term health condition policy incorporates access to healthy food and } \\
\text { recognises poor health as a cause of school absenteeism; policies about urgent care, } \\
\text { when to contact parents, and how to approach referral }\end{array}$ \\
\hline Structures and systems & $\begin{array}{l}\text { Avoid creating hidden places where bullying can occur; respond rapidly to } \\
\text { bullying reports; ensure effective communication with family }\end{array}$ & $\begin{array}{l}\text { Access to private, clean spaces for injecting insulin at school; available refrigeration; } \\
\text { communication with family and health-care professionals who provide ongoing } \\
\text { care; external referral pathways when required }\end{array}$ \\
\hline Human resources & $\begin{array}{l}\text { Include all staff in training on how to recognise and respond to bullying, and } \\
\text { monitor student recreation during lunchtime and other breaks }\end{array}$ & $\begin{array}{l}\text { Include diabetes awareness within staff training (eg, how to recognise a } \\
\text { hypoglycaemic episode at school); access to informed first aid }\end{array}$ \\
\hline Practices & $\begin{array}{l}\text { Be clear about the repercussions of bullying; avoid any potential role modelling } \\
\text { of bullying by teachers; consider curriculum choices-eg, literature that } \\
\text { describes bullying and recovery, provides empathy and compassion, and values } \\
\text { diversity of students; healthy relationship education }\end{array}$ & $\begin{array}{l}\text { Respectfully accommodate requests for breaks (eg, to go to the toilet or get a drink); } \\
\text { consider curriculum choices eg, literature about young people with diabetes that } \\
\text { emphasises participation in usual activities with peers and encourages high } \\
\text { expectations; promotion of diabetes awareness and prevention initiatives }\end{array}$ \\
\hline
\end{tabular}

Practices The professional practices that need to be widely adopted are those that have a positive effect on the determinants of current and future health in children and adolescents. These practices relate to three main domains: maximising educational achievement (inclusion and equity); creating an environment that is favourable to student development; and promoting general competencies and health-related skills (eg, health literacy, basic life knowledge and skills, social and emotional skills)..37 These practices are linked to school management, school policy, physical and social environments, student participation and engagement, relationships with families and the community, school health and social services, and teaching. ${ }_{38}$ Curriculum and pedagogy are as important as each other in developing these practices. The example of bullying (table 1) underlines that key messages and role modelling can be conveyed to students through not only what teachers teach, but also how schools teach and engage with students more generally. Teaching that is based on specific or fragmented objectives is less able than a holistic approach to help students not only to understand the mechanisms of harassment but also to learn how to prevent or resist it.39 To maximise the motivation and agency of education professionals, and thus ensure genuine and sustainable uptake of health-promoting practices in schools, it is crucial to understand the views and practices of those professionals. Understanding the views and the practices of education professionals on health issues in schools should form the basis for the development of more realistic frameworks of practices than those that are currently in place, frameworks that are adapted to context and culture.40 These views and practices are not always shaped by initial and in-service training but are often learned in the field. ${ }_{41}$ Thus, education professionals have a range of visions of their role in health.42 Based on data from the field, there are different ways to contribute to the evolution of educational practices. The most promising ways feature collaborations between practitioners, researchers, designers, technologists, and others to develop practice-based evidence as an essential complement to the findings from other forms of education and public health research.34,43 
Structures and systems The existence of supportive organisational structures at different levels, from national systems through to individual schools, is a condition for successful change. $35,44,45$ Much effort has been invested in education management, especially at the school level..46 $\mathrm{A}$ review by Samdal and Rowling suggests that effective whole school practices are supported by key implementation components, including school leadership and management practices, the school's readiness for change, and the school's organisational and support context.47 Knowing the importance of school management, individual principals are often urged to implement additional policies and programmes in various fields, even though demands on school staff are already excessive.48 The coherence of what is required by schools, especially school management, is crucial; the notion of health as a product of quality schooling should be embedded within schools' core policies, rather than being seen as one among many other additional (ie, secondary) demands. The concept of leadership is often narrowly defined as applying solely to the principal. However, leadership is only a prerequisite for educational change at the individual school level. Schools and communities could expand leadership locally to include representatives across the key stakeholder groups. These groups include students, teachers and other school staff, parents and caregivers, as well as outside service providers. Although the involvement of health professionals will be limited by time and resource constraints, 49 they can be a major asset for schools.

Human resources Evidence shows that professionalism and commitment of school staff are key elements for successful schools.50 The highest performing education systems tend to systematically prioritise the quality of teachers over other strategies to improve education. Current data from the Organisation for Economic Co-operation and Development for countries such as Finland suggest that high performing systems attract the most talented teachers to the most challenging classrooms, and the most capable school leaders to the most disadvantaged schools, which steers all students towards higher academic standards.51 Promoting health in all schools and reducing health inequalities is also a matter of human resources.52 Having political and institutional frameworks is necessary, but without training and capacity building for school staff, progress will

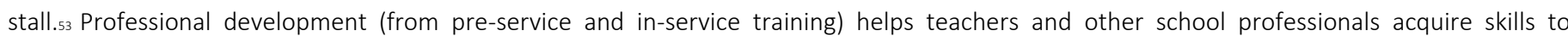
incorporate equitable, inclusive, and health-promoting practices in their classrooms. An educator's view of their role in relation to health is a key determinant of their contribution.40 Education professionals need to be supported in the shift from a physical to a biopsychosocial understanding of health, and from a medical approach to health (seen as health professionals' core business) to a better understanding of their potential effect on health determinants.54 Studies show that teachers who have received health promotion training tend to be more frequently involved in health related projects, and have a more sustainable approach to health education, than those who have not received specific training.54-56 Staff training is not just an assortment of random modules; professional development in health promotion has to be part of a coherent strategy.50 To promote a teacher's continuing education and knowledge management, professional development must extend beyond the early stages of implementation of health programmes.57,58 Teachers who receive ongoing support through specific and timely professional development while, and after, they have opportunities to learn contextually are more likely to continue with newly introduced practices.58 Sustainable professional development is a key condition for a major shift in practices taking place within a school. 59 Support from local health professionals during the design and implementation of staff development programmes can help to cement intersectoral links for mentorship and advice, and enable timely directing of students and families to local health services. Not all programmes in schools are teacher led,20 and so the human resources available to schools could be expanded to include students themselves, in peer-educator roles, or other actors within or beyond the school.

Policies In many national educational policies, health has not been a priority. Indicators of school performance rarely include health, or health education, as a key measure.60 Health improvement is one among many other competing priorities for educational systems and what schools can routinely accomplish. Time is the most scarce resource in schools, not just in low-income countries and low-resource settings, and it is not possible to add an infinite array of new programmes to what schools currently do. Given competing priorities, it is always a question of choice at the national level and at the individual school level. To ensure sustainability, health policies must be embedded within every school's core policies and be coherent with ongoing educational reform processes. In many countries, the development of school health policies can take place within two major areas of reform: the orientation toward more inclusive and equitable schools in the aim of assuring the educational success of all students; and the development of the education for sustainable development and sustainable lifestyles under the umbrella of the SDGs. The views of civil

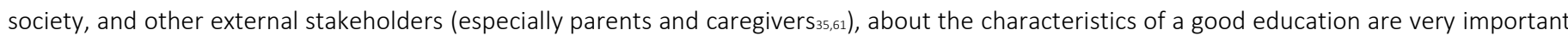
in establishing priorities. Various groups have tried to win support for what they believe are the key problems in schools and for their proposed solutions. ${ }_{35}$ The more powerful and prestigious the groups are, the more likely they are to influence school priorities. The activity of principals and teachers, and the organisation of the school systems, are directly connected to the influence of these groups.62,63 A useful example is the case of programmes that promote abstinence-only-until-marriage. These abstinence-only until-marriage programmes are scientifically and ethically problematic because a large body of evidence supports that they are not effective in delaying initiation of sexual intercourse or changing other sexual behaviours.63 Promotion of such an approach by powerful lobbies-and sometimes governments-can result in the abolition of teaching about sexuality, which then undermines comprehensive approaches to sexuality education in schools. Community expectations shape the school; depending on whether these expectations are oriented towards the wellbeing of students, academic success, or sporting success, for example, the school system will be more or less responsive to efforts to promote different aspects of physical and mental health and wellbeing. Parents' expectations are extremely influential. ${ }_{61}$ Schools' decisions are influenced by their hopes or fears about parental responses to teaching inclusivity and equitability to children, including on topics such as sexuality and gender identity. ${ }_{35}$ Communication with society is indispensable for influencing the views of education policy makers with the aim of scaling up health-promoting practices in schools. Endorsement of school policies by local health professionals can help principals and teachers to allay parental concerns, influence policy makers, and secure resources.

Experience of policy implementation in educational settings The reviews of a large number of educational reforms or innovations, including those that were built on an evidence-based approach, are disappointing. ${ }_{42,64}$ Once implemented and evaluated, education reforms do not always produce the expected effects (in terms of student achievement, scale, or sustainability). ${ }_{65}$ As early as 1995, within the educational research literature, Tyack and $\mathrm{Cuban}_{30}$ attributed the failures of educational reforms to insufficient consideration during the implementation process of the specific school context as well as of staff practices (teachers' so-called grammar of schooling). ${ }_{66}$ Arguably, education professionals simply do not appreciate schools being seen by health policy makers primarily as a neutral platform through which to deliver interventions at scale focused on child and adolescent health. Too often, programmes focus on just a small part of school life or the curriculum and are implemented as a narrow 
intervention that addresses only one specific issue. Such programmes are primarily viewed by educators as having a niche or segmented role and benefit.62 Health-sector professionals who try to implement new approaches might not appreciate the overall coherence of the pedagogy, the constraints that affect the activity (such as collective management, class organisation, heterogeneity of the students, curriculum constraints, and available resources), and the vision and usual practices of staff. ${ }_{34}$ Adapting interventions to existing routines and changing contexts appears to be part of the sustainability process within schools, including for public health interventions.28 There are major differences between schools within a given education system; deviation from the norm is the general rule.67 The so-called standard school does not exist because there are differences in students' needs, rate of teacher and principal turnover, leadership, school size, location (rural or urban), and socioeconomic context. Evidence produced is always contextualised and it is often difficult to draw general conclusions that are relevant for all schools. WHO's Health Promoting School approach originated in the context of high-income countries. It was based on a liberal vision of education, a largely decentralised system that gives real autonomy to schools (eg, to implement a policy), and considers student participation, health, and wellbeing to be core objectives of the school. However, other educational cultures might value academic instruction, involvement in the community, or critical thinking more highly. Schools in low-resource settings are often extremely limited by a scarcity of skilled workforce and funding, and in many centralised contexts the autonomy of schools is minimal. A context-sensitive approach is essential for improving the capacity of schools to promote child and adolescent health, and is a prerequisite for health professionals and researchers who wish to make advances therein. The challenge is to create the best conditions for sustainable changes across different geographical and cultural settings.

Producing and sharing knowledge Studies produced in the context of controlled interventions are especially valuable in showing proof of principle, in comparing outcomes from different models, and in understanding cost-effectiveness. However, the necessary evidence to support the scaling up and sustainability of holistic approaches to health in schools is not limited to data produced in the experimental contexts that are well known to, and arguably most valued by, health professionals and health-services researchers. Programmes that work in one setting often do not work in another. ${ }_{42}$ Programmes supported through external interventions or dedicated grants might not last in their entirety (or at all) once the funding ends.28 The double translation process from international guidelines such as the WHO Health Promoting School approach, to national and local policies has been shown to be highly complex.68 There is a need for inclusion of a wide range of relevant and robust evidence in this global discussion, 69 such as evidence about: practices to promote health in school, contexts and cultures, determinants of inequalities, change within the educational systems, and factors affecting the implementation of health-promoting practices.36 Different kinds of data are required to examine each area.70 A reasoned understanding of which data can best be produced in experimental conditions, and which data can best suit observation in everyday practice, is required. In all cases, combining scientific quality and relevance for professionals will be needed. Valuing what is already done, and sharing best practices and improving them using the evidence produced by research, are relevant approaches (eg, the recommendations from the Aspen Institute National Commission on Social, Emotional, and Academic Development, ${ }_{11}$ and Sherer and colleagues 72 ). Without such a strategy, there is a high risk of having a minimal effect on the educational service offered to students. More multidisciplinary research that combines the strengths and traditions of health and education with meaningful codesign with teachers and students will also benefit the field.

Building bridges between education and health: the role of health professionals Schools need a truly intersectoral partnership to maximise their potential in shaping children's and adolescents' health knowledge, attitudes, behaviours, and health outcomes. The levers to optimise the health of children and adolescents are shared by families, communities, policy makers, and professionals from health, social, and education sectors. The involvement of health professionals can be a powerful asset in gaining support for whole school endeavours. Since the population often views health from a medical or disease orientation, support from health professionals and health policy makers is, arguably, one of the main enablers of the development of the contribution of schools to health. The question is how health professionals can support schools at national and local levels to move beyond the rhetoric and make real, sustainable changes to strengthen every school's capacity as a healthy place to live, learn, and work.2 The current COVID-19 pandemic has brought unprecedented attention to schools, education, and health. Attention has extended well beyond infection control against severe acute respiratory syndrome coronavirus 2, to wider appreciation of the effect of school closures on student and parent mental health and wellbeing. This attention provides new opportunities to develop closer working relationships between health and education professionals in schools, and effective local partnerships between health and education professionals have been reported to have contributed to the successful reopening of schools.73 During the pandemic, it is pleasing to see the breadth of roles that have been articulated for health professionals, such as school nurses, who can "assess the data available, integrate it into prior knowledge about infection control, capitalise on emergency preparedness planning, advocate for equitable distribution of services, access evidence-based resources, plan for interventions in the schools, and constantly evaluate outcomes to improve approaches".74 Table 2 shows multiple ways in which health professionals can make a concrete contribution to intersectoral actions.

\begin{tabular}{|c|c|c|}
\hline & Roles for health-care professionals & Action points \\
\hline $\begin{array}{l}\text { Advocacy for health } \\
\text { promotion in school }\end{array}$ & $\begin{array}{l}\text { Health professionals reinforce the legitimacy of } \\
\text { schools, value schools' expertise in health } \\
\text { improvement, and advocate for inclusive, } \\
\text { equitable, and healthy school }{ }^{35}\end{array}$ & $\begin{array}{l}\text { Broaden stakeholders' understanding of the social determinants that influence health and development; } \\
\text { advocate for inclusion and equity in school policies and practices; contribute to the recognition of a school's } \\
\text { contribution to health improvement and health inequality reduction; reposition health promotion in schools, } \\
\text { from implementation of programmes in schools to holistic improvement of the practices that affect health } \\
\text { determinants in the everyday life of students at school; reframe health interventions in schools, moving from } \\
\text { typical prevention lectures on health topics to capacity building among school staff }\end{array}$ \\
\hline $\begin{array}{l}\text { Education and prevention } \\
\text { of health issues }\end{array}$ & $\begin{array}{l}\text { Health-care professionals have an important } \\
\text { educational role for children, adolescents, and } \\
\text { their families in synergy with schools" }\end{array}$ & $\begin{array}{l}\text { During consultations in health settings (medical and dental consultations, community pharmacies), include } \\
\text { questions to value what is done in schools to promote health (eg, asking what they learnt about a particular } \\
\text { health topic at school); contribute to a health promotion programme when it is implemented; take part in } \\
\text { health initiatives that target children and adolescents at community level }\end{array}$ \\
\hline $\begin{array}{l}\text { Medical contribution to } \\
\text { education and learning }\end{array}$ & $\begin{array}{l}\text { Addressing medical problems that can inhibit } \\
\text { education and learning is a role shared by } \\
\text { school health services and community health } \\
\text { professionals }\end{array}$ & $\begin{array}{l}\text { School health services can manage physical and psychological health issues that might inhibit learning, growth, } \\
\text { and development; support school-based delivery of preventive services (eg, vaccination programmes, } \\
\text { deworming programmes, administration of iron and folate) }\end{array}$ \\
\hline $\begin{array}{l}\text { Development of schools' } \\
\text { capacity to promote health }\end{array}$ & $\begin{array}{l}\text { Promote health through intersectoral } \\
\text { engagement with education professionals }\end{array}$ & $\begin{array}{l}\text { Support local school projects that aim to affect health determinants (both directly in health, and indirectly } \\
\text { through educational success, citizenship, etc); contribute to building motivation and agency of teachers by } \\
\text { intersectoral work, and formal or informal training }\end{array}$ \\
\hline
\end{tabular}


Of course, the commitment of health professionals depends on the context, including the nature of the activity, the existence of an appropriate participation framework, and the availability of practical support required to free up time to perform these roles. One simple example of a strategy that health professionals can use to make an intersectoral contribution is by asking children and adolescents (and parents or caregivers) during health consultations, whether within a doctor's office or a community pharmacy, about what they have learnt at school regarding a particular health topic, and how it was different or similar to what they had learnt at home. Health professionals, whether in a doctor's office or a community pharmacy, can also show that they value what health promotion is being done in schools, which means knowing what is being done in schools. The contribution of health professionals must move from a narrow focus on children with specific health issues (eg, HIV/AIDS, or asthma), to all students. Likewise, sharing information with students and school principals about the range of disease prevention and health promotion approaches that are being undertaken within different sectors, including schools and health services, can achieve greater intersectoral understanding within the systems that support health and learning.

Health professionals as catalysts for healthy changes in schools Supporting every school to become a foundation for healthy lives means creating the conditions for schools to be inclusive (every child in school), equitable (ensuring the success of all children), and healthy (providing a learning environment that promotes health both now and in the future). The core business of schools is focused on increasing educational outcomes rather than the reduction of health problems, despite knowledge of how closely these objectives are intertwined.4Schools should not be considered simply as convenient platforms for the implementation of prevention programmes, or as spaces to deliver expert knowledge about the importance of lifestyle for preventing diseases. Data show that when schools are considered only as convenient platforms or spaces to introduce interventions, there is a high risk that the intervention might increase inequalities.75 The challenge is for better appreciation of the multiplicity of ways that health promotion can be understood as a means for schools to achieve educational goals. To have a substantial effect on health promotion in the school setting, stronger alliances between education and health professionals must be created at various organisational levels. At a global level, initiatives seek to learn lessons from the enactment of successful reforms and change in education, and contribute to forging a common culture to support schools, including in their efforts to promote student health. These goals are shared by global initiatives such as the UN interagency collaboration for a new approach to school health known as "Stepping up effective school health and nutrition", the Global Standards for Health Promoting Schools (a joint initiative between UNESCO and WHO), 76 and the UNESCO Chair and WHO Collaborating Centre in Global Health and Education. 77 Wider collaboration between international and national professional groups and coalitions that are mindful of the challenges noted in the literature and described here offers a genuine roadmap to production of action-oriented knowledge and to sharing of improvement strategies. Notwithstanding these efforts to promote health, greater cooperation and mutual support of local health and education professionals is essential to achieve our global ambition for schools to be the means through which the world's children and adolescents develop the capabilities for lifelong health, wellbeing, and success. Health professionals' support for school activities related to health is a key factor for sustainable health-promoting practices in schools. Rooted in their communities, cognisant of the prevailing culture and context, and intimately involved in the lives of local families, health professionals represent a formidable force as we ride this next wave of change.

Contributors DJ and NJG conceptualised the article and led the writing of the paper with SMS. All authors contributed to drafting and revising the manuscript, and approved the final draft. Declaration of interests SMS reports grants from WHO on Health Promoting Schools during the writing of the Viewpoint, and was also a member of WHO's School Health Services Guideline Development Group. The other authors declare no competing interests. Acknowledgments MYF is associated with NCD Child. NCD Child is supported through grants to the Hospital for Sick Kids (SickKids, Toronto, Canada), from the AstraZeneca Young Health Program and Novo Nordisk. SickKids also provides in-kind contributions to support the NCD Child Secretariat. DJ and NJG are associated with the UNESCO Chair Global Health and Education and WHO Collaborating Centre for Research in Education and Health. UNESCO Chair Global Health and Education and WHO Collaborating Centre for Research in Education and Health are supported by the non-profit organisations MGEN (Mutuelle Générale de l'Education Nationale, France) and Groupe VYV (France). Université Clermont-Auvergne (Chamalières, France) provides in-kind contributions to support the UNESCO Chair secretariat.

Search strategy and selection criteria We searched PubMed for relevant papers from Jan 1, 1980, to Aug 31, 2020, using the search term "health in schools". Papers and books were also identified through searches of our own files and publications. Only publications in English and French were included. The final reference list was based on the relevance to the broad scope of this Viewpoint.

\section{References}

1 Viner RM, Ozer EM, Denny S, et al. Adolescence and the social determinants of health. Lancet 2012; 379: 1641-52.

2 WHO. Thematic paper 2: schools and pre-schools promoting health and well-being for all children and adolescents. 2016. http://www.euro.who.int/_data/assets/pdf_file/0010/324658/Thematic-Paper-2-Education.pdf (accessed July 27, 2020).

3 Patton GC, Olsson CA, Skirbekk V, et al. Adolescence and the next generation. Nature 2018; 554: 458-66.

4 St Leger L, Young I, Blanchard C, Perry M. Promoting health in schools: from evidence to action. IUHPE Factsheet. 2010. https://www.iuhpe.org/images/PUBLICATIONS/THEMATIC/HPS/Evidence-Action ENG.pdf (accessed July 27, 2020).

5 Alemán-Díaz AY, Backhaus S, Siebers LL, et al. Child and adolescent health in Europe: monitoring implementation of policies and provision of services. Lancet Child Adolesc Health 2018; 2: 891-904.

6 WHO. Global school health initiatives: achieving health and education outcomes. 2017. https://www.who.int/publications-detail/global-school-health-initiatives-achieving-health-andeducationoutcomes (accessed July 27, 2020).

7 UN Educational, Scientific and Cultural Organization, Global Partnership for Education, Food and Agriculture Organization of the UN, et al. Stepping up effective school health and nutrition. 2020. https://unesdoc.unesco.org/ark:/48223/pf0000373431 (accessed July 31, 2020).

8 Haeck C, Lefebvre P. Pandemic school closures may increase inequality in test scores. Can Public Policy 2020; 46: 82-87.

9 Jourdan D, Marmot M, Gray N. Coronavirus: there is an urgent need to re-open schools-this is how to make it happen. May 5, 2020. https://theconversation.com/coronavirus-there-isanurgent-need-to-re-open-schools-this-is-how-to-make-ithappen-137818 (accessed July 19, 2020).

10 Nourrisson D. Education à la santé: XIX-XX siècle. Rennes, France: Ecole Nationale de la Santé Publique, 2002.

11 WHO. What is a health promoting school?. 2019. https://www.who.int/school youth health/gshi/hps/en/ (accessed July 27, 2020).

12 Allensworth DD, Kolbe LJ. The comprehensive school health program: exploring an expanded concept. J Sch Health 1987; 57: 409-12.

13 Chiang RJ, Meagher W, Slade S. How the whole school, whole community, whole child model works: creating greater alignment, integration, and collaboration between health and education. J Sch Health 2015; 85: 775-84

14 UN Educational, Scientific and Cultural Organization. UNESCO strategy on education for health and well-being: contributing to the sustainable development goals. 2016. https://unesdoc.unesco.org/ark:/48223/pf0000246453 (accessed July 27, 2020). 
15 Leahy D, Simovska V. Critical perspectives on health and wellbeing education in schools. Health Educ 2017; 117: 430-33.

16 Paulus P. Anschub.de ein Programm zur Förderung der guten gesunden Schule. Munster, Germany: Waxmann Verlag, 2009.

17 FRESH Monitoring and Evaluation Coordinating Group. Monitoring and evaluation guidance for school health programs. 2014. https://hivhealthclearinghouse.unesco.org/library/documents/monitoring-and-evaluation-guidance-school-healthprograms-eight-core-indicators (accessed July 27, 2020).

18 Patton GC, Bond L, Carlin JB, et al. Promoting social inclusion in schools: a group-randomized trial of effects on student health risk behavior and well-being. Am J Public Health 2006; 96 : $1582-87$.

19 Langford R, Bonell C, Jones H, et al. The World Health Organization's health promoting schools framework: a Cochrane systematic review and meta-analysis. BMC Public Health 2015; 15: 130 .

20 Shinde S, Weiss HA, Varghese B, et al. Promoting school climate and health outcomes with the SEHER multi-component secondary school intervention in Bihar, India: a cluster-randomised controlled trial. Lancet 2018; 392: 2465-77.

21 Roder-Dewan S, Akala FA, Veillard J. Human capital and health. June 10, 2019. https://blogs.worldbank.org/health/human-capitaland- health (accessed Sept 9, 2020).

22 UN. Transforming our world: the 2030 agenda for sustainable development. 2015. https://sustainabledevelopment.un.org/post2015/transformingourworld (accessed July 27, 2020).

23 Barry MM, Clarke AM, Jenkins R, Patel V. A systematic review of the effectiveness of mental health promotion interventions for young people in low-and middle-income countries. BMC Public Health 2013; 13: 835 .

24 Durlak JA, Weissberg RP, Dymnicki AB, Taylor RD, Schellinger KB. The impact of enhancing students' social and emotional learning: a meta-analysis of school-based universal interventions. Child Dev 2011; 82: 405-32.

25 Weare K, Nind M. Mental health promotion and problem prevention in schools: what does the evidence say? Health Promot Int $2011 ; 26$ (suppl 1): $29-69$.

26 Jason LA, Curie CJ, Townsend SM, Pokorny SB, Katz RB, Sherk JL. Health promotion interventions. Child Fam Behav Ther 2002; 24: 67-82.

27 WHO. Making every school a health promoting school. 2018. http:// www.who.int/health-promoting-schools/making-every-schoolhealth-promotion-school/en/ (accessed July 27, 2020). 28 Herlitz L, MacIntyre H, Osborn T, Bonell C. The sustainability of public health interventions in schools: a systematic review. Implement Sci 2020; 15: 1-28.

29 Jourdan D, Lombrail P. La santé des enfants et des adolescents en milieu scolaire: dix mesures pour une politique de santé à l'Ecole à la hauteur des défis de notre temps. Rapport aux ministres de l'éducation et de la santé. May, 2015. http://didier-jourdan.com/fr/2016/11/16/sante-des-enfants-et-des-adolescents-en-milieuscolaire/ (accessed July 27, 2020).

30 Tyack DB, Cuban L. Tinkering toward utopia. Cambridge, MA: Harvard University Press, 1995

31 Kirtman L, Fullan M. Leadership: key competencies for whole-system change. Bloomington, IN: Solution Tree Press, 2015.

32 Viennet R, Pont B. Education policy implementation: a literature review and proposed framework. Paris: Éditions OCDE, 2017.

33 Fuller K, Stevenson H. Global education reform: understanding the movement. Educ Rev 2019; 71: 1-4.

34 Cèbe S, Goigoux R. Lutter contre les inégalités: outiller pour former les enseignants. Rech Formation 2018; 87: 77-96.

35 United Nations Educational, Scientific and Cultural Organization. A guide for ensuring inclusion and equity in education. 2017. https://unesdoc.unesco.org/ark:/48223/pf0000248254 (accessed July 27, 2020)

36 Schools for Health in Europe. School health promotion-evidence for effective action on inequalities. 2018. https://www.schoolsforhealth.org/sites/default/files/editor/fact-sheets/she factsheet no 4 2018.pdf (accessed July 27, 2020).

37 St Leger L. Protocols and guidelines for health promoting schools. Promot Educ 2005; 12: 145-47.

38 Pommier J, Guével M-R, Jourdan D. Evaluation of health promotion in schools: a realistic evaluation approach using mixed methods. BMC Public Health 2010; 10: 43.

39 Barry MM, Clarke AM, Dowling K. Promoting social and emotional well-being in schools. Health Educ 2017; 117: 434-51.

40 Jourdan D, Pommier J, Quidu F. Practices and representations of health education among primary school teachers. Scand J Public Health 2010; 38: 86-94.

41 Jourdan D, Mannix-McNamara P, Simar C, Geary T, Pommier J. Factors influencing the contribution of staff to health education in schools. Health Educ Res 2010; 25: 519-30.

42 Bryk AS, Gomez L, Grunow A, LeMahieu P. Learning to improve: how America's schools can get better at getting better. Cambridge, MA: Harvard Education Publishing, 2015

43 LeMahieu PG, Edwards AR, Gomez LM. At the nexus of improvement science and teaching: introduction to a special section of the Journal of Teacher Education. J Teach Educ 2015; 66 : 446-49.

44 Weick KE. Educational organizations as loosely coupled systems. Adm Sci Q 1976; 21: 1-19.

45 Jones SM, Bouffard SM. Social and emotional learning in schools: from programs to strategies and commentaries. Soc Policy Rep 2012; 26: 1-33.

46 Campbell DW, Fullan M. The governance core: school boards, superintendents, and schools working together. Thousand Oaks, CA: Corwin Press, 2019.

47 Samdal O, Rowling L. The implementation of health promoting schools: exploring the theories of what, why and how. Abingdon, UK: Routledge, 2012.

48 Bryk AS. 2014 AERA distinguished lecture: accelerating how we learn to improve. Educ Res 2015; 44: 467-77.

49 Gautier A. Baromètre santé médecins généralistes 2009. 2011. http://peidd.fr/IMG/pdf/Barometre Sante medecins generalistes 2011.pdf (accessed July 27, 2020).

50 Jourdan D. Health education in schools: the challenge of teacher training. Paris, France; Institut National de Prévention et d'Éducation pour la Santé: 2011.

51 Organisation for Economic Co-operation and Development. OECD yearbook 2015. Paris, France: OECD Publishing, 2015. https://www.oecd-ilibrary.org/economics/oecdobserver/volume-2015/issue-1 observer-v2015-sup1-en (accessed July 27, 2020).

52 Pont B, Nusche D, Moorman H. Improving school leadership, vol 1: policy and practice. Paris, France: OECD Publishing, 2008.

53 Schleicher A. Preparing teachers and developing school leaders for the 21st century: lessons from around the world. Paris, France: OECD Publishing, 2012.

54 Simar C, Jourdan D. Education et santé à l'école: étude de l'impact d'un dispositif de formation et d'accompagnement sur l'implication des enseignants dans une démarche de promotion de la santé. Rech Éduc 2010; 3.

55 Speller V, Marks R, Byrne J et al. Developing trainee school teachers' expertise as health promoters. Health Educ 2010; 110: 490-507.

56 Byrne J, Pickett K, Rietdijk W, Shepherd J, Grace M, Roderick P. A longitudinal study to explore the impact of preservice teacher health training on early career teachers' roles as health promoters. Pedagogy Health Promot 2016; 2: 170-83.

57 Moffett CA. Sustaining change: the answers are blowing in the wind. Educ Leadersh 2000; 57: 35-38.

58 Thompson S. Creating a high-performance school system. Phi Delta Kappan 2003; 84: 488-95.

59 Gleddie DL, Robinson DB. Creating a healthy school community? Consider critical elements of educational change. J Phys Educ Recreat Dance 2017; 88: 22-25.

60 Wyse D, Hayward L, Pandya J. Handbook of curriculum, pedagogy and assessment. London, UK: Sage, 2015.

61 Law B. Moral panic 101. Sept, 2017. https://www.quarterlyessay.com.au/essay/2017/09/moral-panic-101 (accessed July 27, 2020).

62 Rasberry CN, Slade S, Lohrmann DK, Valois RF. Lessons learned from the whole child and coordinated school health approaches. J Sch Health 2015; 85: 759-65.

63 Santelli JS, Kantor LM, Grilo SA, et al. Abstinence-only-until marriage: an updated review of US policies and programs and their impact. J Adolesc Health 2017; 61: 273-80.

64 Prost A. Du changement dans l'école. Les réformes de l'éducation de 1936 à nos jours. Paris: Seuil; 2013.

65 Fullan M. Leading in a culture of change. Revised edn. San Francisco, CA: Jossey-Bass, 2007.

66 Tyack D, Tobin W. The "grammar" of schooling: why has it been so hard to change?. Am Educ Res J 1994; 31: 453-79. 
67 Organisation for Economic Co-operation and Development. PISA 2015 results (volume I)-excellence and equity in education. Paris: OECD Publishing, 2016. http://www.oecd.org/education/pisa-2015-results-volume-i-9789264266490-en.htm (accessed July 27, 2020).

68 Nordin LL, Jourdan D, Simovska V. (Re)framing school as a setting for promoting health and well-being: a double translation process. Crit Public Health $2019 ; 29: 325-36$.

69 Caldwell DM, Davies SR, Hetrick SE et al. School-based interventions to prevent anxiety and depression in children and young people: a systematic review and network meta-analysis. Lancet Psychiatry 2019; 6: 1011-20.

70 Rowling L, Jeffreys V. Capturing complexity: integrating health and education research to inform health-promoting schools policy and practice. Health Educ Res 2006; 21: 705-18.

71 The Aspen Institute National Commission on Social, Emotional, and Academic Development. From a nation at risk to a nation at hope, recommendations from the National Commission on Social, Emotional, \& Academic Development 2018. http://nationathope.org/report-from-the-nation-download/ (accessed July 27, 2020).

72 Sherer D, Norman J, Bryk AS, et al. Evidence for improvement: an integrated analytic approach for supporting networks in education. February, 2020. https://www.carnegiefoundation.org/resources/publications/evidence-for-improvement/ (accessed Aug 3, 2020).

73 UN Educational, Scientific and Cultural Organization Chair in Global Health and Education. Successes and challenges of the reopening process. June, 2020. https://unescochairghe.org/resources/themes-covid-19/preview-survey-school-reopening/successes-and-challenges-of-the-reopening-process/ (accessed Aug 3, 2020).

74 McDonald CC. Reopening schools in the time of pandemic: look to the school nurses. J Sch Nurs 2020; 36: 239-40.

75 Qadri G, Alkilzy M, Franze M, Hoffmann W, Splieth C. School-based oral health education increases caries inequalities. Community Dent Health $2018 ; 35: 153-59$.

76 WHO. Global standards for health promoting schools. Concept note. October, 2018. https://www.who.int/publications/i/item/globalstandards-for-health-promoting-schools (accessed Aug 3, 2020).

77 UN Educational, Scientific and Cultural Organization Chair and WHO Collaborating Centre in Global Health and Education. Connecting knowledge, taking on children's future. 2018. https://unescochair-ghe.org/wp-content/uploads/2018/04/Brochure-UNESCO-UNITWIN-April-2018.pdf (accessed Aug 3, 2020). 